\title{
Evaluation of Celiac Trunk, Hepatic Artery Variations, and Their Collateral Arteries by Multi-Slice Computed Tomography
}

\author{
(D) Fatih Cankal,' (1) Mustafa Kaya, ${ }^{2}$ (1) Mehmet Ali Guner ${ }^{3}$ \\ 'Department of Anatomy, Ankara Medipol University Faculty of Medicine, Ankara, Turkey \\ ${ }^{2}$ Department of Radiology, Gazi University Faculty of Medicine, Ankara, Turkey \\ ${ }^{3}$ Department of Anatomy, Health Sciences University, Gulhane Faculty of Medicine, Ankara, Turkey
}

\begin{abstract}
Objectives: Celiac Trunk (CT) is a vital artery and the first unmatched branch of the abdominal aorta, providing blood to upper abdominal structures, particularly the liver, stomach, and spleen. It is essential to know its anatomy in terms of pancreas, spleen, gallbladder, liver surgeries, and interventional radiological procedures such as chemoembolization. The aim of our study is to contribute to the literature with the measurements of distances between the diaphragmatic crus and vascular structures with their diameters, which have been studied insufficiently, and to detect the possible relationships between vascular variations and collateral branches.

Methods: Imaging findings of 200 patients (114 males and 86 females), who underwent Multi-Section Computed Tomography examination with various indications in our center between June 2016 and July 2020, were retrospectively analyzed. The statistical relations between CT and Hepatic Artery variations, collateral formations, age, and gender were evaluated with the Spearman's Rho Correlation Coefficient Test.

Results: The distance between the crus of diaphragm and CT was 4-60 mm (mean $24.3 \mathrm{~mm}$ ), the distance between CT and superior mesenteric artery (SMA) was 2.5-35 mm (mean $8.6 \mathrm{~mm}$ ), CT diameter was 4.6-9.4 mm (mean 7.3 mm), and the main hepatic artery diameter was $2.4-5.8 \mathrm{~mm}$ (mean $4.1 \mathrm{~mm}$ ). There was no correlation in our study between CT, Hepatic Artery variations, and their collaterals ( $r$ in range of $-20,124-0.116, p>0.05$ ). It can be said that in cases of the single accessory left hepatic artery originating from the left gastric artery, such as Michel's Type V and Type VIII, collaterals between common hepatic artery and SMA were relatively more frequent $(p=0.1)$.

Conclusion: Our study contributed to the literature by measuring the distance between diaphragmatic crus-vascular structures, which has been little studied in the past. Frequencies of CT and Hepatic Artery variations that have been detected in our study are similar to the results of the previous studies with non-malignancy patient groups.
\end{abstract}

Keywords: Anatomical variation; celiac trunk; collateralization; hepatic artery.

Please cite this article as "Cankal F, Kaya M, Guner MA. Evaluation of Celiac Trunk, Hepatic Artery Variations, and Their Collateral Arteries by Multi-Slice Computed Tomography. Med Bull Sisli Etfal Hosp 2021;55(2):217-223".

C eliac trunk (CT) is the first unpaired branch of the abdominal aorta and it is essential for surgeries as providing blood for upper abdominal structures, especially the liver, stomach, and spleen. Pre-operative detection of the celiac artery and its branch common hepatic artery (CHA) variations helps to prevent unexpected bleeding or isch- 
emia and to ensure the most effective results in planning interventional radiological procedures such as chemoembolization. ${ }^{[1-4]}$

Digital subtraction angiography (DSA) is still accepted as the gold standard in demonstrating vascular structures; however, it is now used much less frequently due to the fact that it is an invasive procedure that has the risks of serious complications. At present, multi-slice computed tomography (MSCT) examination is primarily preferred instead. ${ }^{[5]}$

In our study, variations of CT and hepatic arteries with possible collateralizations in patients who had MSCT images due to colorectal carcinoma were examined. Our research is primarily concerned with radiological anatomy. The reason we chose colorectal cancer patients as the study group is to see if the frequency of variations in the celiac artery, hepatic artery, and their collaterals differs between patients with colorectal cancer and healthy people. If the variation and collateral frequencies differ, we hoped to make predictions about what might be causing this difference and to spark a preliminary discussion for future studies that could be conducted with different groups.

\section{Methods}

This study was approved by the Local Ethics Committee (74791132-604.01.01/722).

A total of 200 patients (114 males and 86 females), who were diagnosed with a colorectal cancer and had not undergone any surgery involving the celiac or superior mesenteric arteries, scanned with MSCT for various indications in our center between June 2016 and July 2020 were included in the study. The age range of the patients was between 22 and 88 years and MSCT images were evaluated retrospectively by two radiologists. The examinations were performed with General Electric IQ ${ }^{\mathrm{TM}}$ 32-Detector Spiral MSCT device with 120-130 kV tube voltage using 200-360 $\mathrm{mAs}$ value within $1.25 \mathrm{~mm}$ section thickness.

All patients were administered $1.5-2 \mathrm{ml} / \mathrm{kg}$ non-ionic contrast agent at 3-5 ml/s rate, and the images were taken in the arterial and portal phases after the intravenous contrast agent.

Inferior phrenic arteries, $\mathrm{CT}$, and superior mesenteric artery (SMA) were defined in the images. Then, the distances between diaphragmatic crus and separation point of $\mathrm{CT}$ from aorta and between CT and SMA were measured. In addition, the diameters of $\mathrm{CT}$ and $\mathrm{CHA}$ were included to the measurements.

The variations of $C T$ and hepatic arteries were evaluated, respectively. Branching pattern of $\mathrm{CT}$ was distinguished according to the Uflacker's Classification, while the variations of hepatic arteries were categorized with the Michels' and Hiatt's classification. ${ }^{[6-8]}$ The presence and arising points of common inferior phrenic artery (CIPA), right inferior phrenic artery (RIPA), and left inferior phrenic artery (LIPA) were recorded.

Collateral arteries were identified.

\section{Statistical Analysis}

The statistical relations between $\mathrm{CT}$ and $\mathrm{CHA}$ variations, collateral formations, age, and gender were evaluated with the Spearman's Rho Correlation Coefficient Test. All statistical analyses were performed with the SPSS ${ }^{\mathrm{TM}}$ version 22 software (IBM Corporation NY, USA), and the level of significance was taken as $\mathrm{\alpha}=0.05$.

\section{Results}

The mean age was 62.78 years, the standard deviation was 11.42 years, the interquartile range was between 57 and 70 years.

The distance between the diaphragm crus and $\mathrm{CT}$ varied considerably, ranging from $4 \mathrm{~mm}$ to $60 \mathrm{~mm}$ (mean 24.3 $\mathrm{mm}$ ). The distance between the CT and SMA was between $2.5 \mathrm{~mm}$ and $35 \mathrm{~mm}$ (mean $8.6 \mathrm{~mm}$ ). The diameters of CT and CHA were 4.6-9.4 mm (mean 7.3 mm) and 2.4-5.8 mm (mean $4.1 \mathrm{~mm}$ ), respectively.

The types and frequency of celiac artery variations according to the Uflacker classification are summarized in Table 1. The types and frequency of hepatic artery variations according to the Michels and Hiatt classifications are shown in Tables 2 and 3.

Collateralization was found in 30 cases (15\%). These anastomoses were observed between the branches of SMA and the branches of CHA in 20 cases (10\%), the branches of splenic artery (SA) and the branches of SMA in six cas-

Table 1. Distribution of celiac artery variations by Uflacker classification

\begin{tabular}{lcc}
\hline Type & Variation & Number (\%) \\
\hline I & Complete trifurcation & $185(92.5)$ \\
& Classical & $74(37.0)$ \\
II & Non-classical & $111(55.5)$ \\
III & Hepatosplenic trunk & $2(1.0)$ \\
IV & Hepatogastric trunk & $1(0.5)$ \\
V & Hepato spleno gastric trunk & $1(0.5)$ \\
VI & Gastrosplenic trunk & $7(3.5)$ \\
VII & Celiacomesenteric trunk & $2(1.0)$ \\
VIII & Celiacocolic trunk & $0(0.0)$ \\
Total & Absence of celiac trunk & $2(1.0)$ \\
\hline
\end{tabular}


Table 2. Distribution of hepatic artery variations by Michels classification. LHA, RHA, LGA, SMA, and CHA

\begin{tabular}{lcc}
\hline Type & Variation & Number (\%) \\
\hline I & Normal pattern & $115(57.5)$ \\
II & Replaced LHA from LGA & $19(9.5)$ \\
III & Replaced RHA from SMA & $22(11 / 0)$ \\
IV & Replaced RHA and LHA & $8(4.0)$ \\
V & Accessory LHA & $20(10.0)$ \\
VI & Accessory RHA & $2(1.0 \%)$ \\
VII & Accessory RHA and LHA & $3(1.5 \%)$ \\
VIII & Replaced RHA or LHA with & $4(2.0)$ \\
& other hepatic artery being & \\
IX & an accessory one & \\
X & CHA as a branch of SMA & $3(1.5)$ \\
Out of the & CHA as a branch of LGA & $0(0.0)$ \\
Michels & CHA as a branch of Aorta & $4(2.0)$ \\
classification & & \\
Total & & \\
\hline
\end{tabular}

LHA: Left hepatic artery; RHA: Right hepatic artery; LGA: Left gastric artery; SMA: Superior mesenteric artery; CHA: Common hepatic artery.

Table 3. Distribution of hepatic artery variations by Hiatt classification. LHA, RHA, SMA, and CHA

\begin{tabular}{lcc}
\hline Type & Variation & Number (\%) \\
\hline I & Normal pattern & $115(57.5)$ \\
II & Replaced or accessory LHA & $39(19.5)$ \\
III & Replaced or accessory RHA & $24(12.0)$ \\
IV & Replaced or accessory LHA and RHA & $15(7.5)$ \\
V & CHA as a branch of SMA & $3(1.5)$ \\
VI & CHA as a branch of Aorta & $4(2.0)$ \\
Total & & $200(100.0)$ \\
\hline
\end{tabular}

LHA: Left hepatic artery; RHA: Right hepatic artery; SMA: Superior mesenteric artery; $\mathrm{CHA}$ : Common hepatic artery.

es (3\%), the branches of left gastric artery (LGA), and the branches of SMA in four cases (2\%). According to the Michel's classification, CHA-SMA collateralization was detected in nine of the 116 Type I variations, in one of the 21 Type II variations, in two of the 23 Type III variations, in two of the eight Type IV variations, in five of the 20 Type $V$ variations, and in one of the four Type VIII variations. No collateral formations were found in cases with Type VI, Type VII, and Type IX variations.

No statistical correlation was detected between variations of celiac artery-hepatic artery variations, and age or gender. Moreover, there were no correlations between celiac artery-hepatic artery variations, and collateral formations ( $r$ in range of $-0.124-0.116, p>0.05)$. Statistically, the lowest $p$ value ( $p=0.1$ ) was found between CHA-SMA collaterals and Michel's variations.

\section{Discussion}

DSA is considered the gold standard in the assessment of vascular structures. However, in some variations, it is also possible that some structures may be overlooked because the vascular structure originates from points far from the expected localizations in selective angiography. ${ }^{[9]}$ Also in MSCT examinations, the vascular structures can be shown in detail with short-term breath-holding.

The form of CT stated in anatomical textbooks consisting of LGA, CHA, and SA is called complete CT. While all three branches rise at the same point in the classical appearance, this is not as common as one of these three branches separated earlier which is called non-classical complete CT.

Normal mesenteric vascular anatomy consists of three branches separated from the aorta. These branches are CT, SMA, and inferior mesenteric artery. CT is generally divided into three branches. The first branch is LGA. The second branch is the SA, giving rise to the dorsal and caudal pancreatic arteries, short gastric arteries, left gastroepiploic artery, and posterior gastric artery branches. The third and other major branch is CHA and the first branch of CHA is the gastroduodenal artery (GDA). After the GDA branch, the right gastric artery and the right hepatic artery (RHA) and left hepatic artery (LHA) branches are separated. ${ }^{[10]}$

The type described by Vesalius in 1543 is in the form of non-classical CT and showed LGA as the branch of SA. ${ }^{[1]}$

In 1928, Adachi and Hasebe first classified the variations on $\mathrm{CT}$ and its branches, ${ }^{[12]}$ Michel's grouped these variations into ten main groups. ${ }^{[7]}$

The reason why the variation rates were higher in some cadaveric studies compared to radiological studies may be attributed to the insufficiency of opacification of very thin vessels. However, in some evaluations, it is argued that radiological studies are more advanced in showing variations. ${ }^{[13]}$

Von Haller, a Swiss anatomist, and physiologist were the first to describe CT branches and their variation and in some references, this structure is still called the Tripus Halleri. ${ }^{[14]}$

CT variations have been reported between $9 \%$ and $13 \%$ in large series. Aslaner et al. showed the presence of $13.4 \%$ CIPA, 32.4\% RIPA, and 42.2\% LIPA rising from $\mathrm{CT}^{\text {. }}{ }^{[15]}$

Incomplete CT subtypes were reported with a rate of 1.7$25.3 \%$, and gastrosplenic trunk (GST) (3-4\%), hepatosplenic trunk (HST) (2-5\%), and hepatogastric trunk (HGT) was found to be $<1 \%$. The absence of $C T$ has been reported to 
be between $0.19 \%$ and $0.4 \% \cdot{ }^{[16]}$ Celiacomesenteric trunk (CMT) varies between $0.3 \%$ and $0.62 \%$, and incomplete CMT between $0.16 \%$ and $0.37 \% .{ }^{[13,17]}$ Celiacomesenteric anastomoses were found between $0.04 \%$ and $0.13 \%{ }^{[13]}$ There are other variations for the CT that is not included in the known classifications. ${ }^{[18,19]}$

The similarity of vascular variation frequencies in patients with colorectal cancer who underwent abdominal MSCT examinations with groups without malignancy suggests that vascular variations are not associated with the development of malignancy.

In the review publication of Matusz, it was shared that the absence of CT was reported as $0-2 \%$ (mean 0.11 ) in cadaver dissection studies, $0-1.11 \%$ (mean 0.35 ) in surgical series, and $0.1-1 \%$ (mean 0.12 ) in radiological studies. ${ }^{[17]}$ (Fig. 1)

After Adachi and Hasebe classified the $C T$ variations in 1928, Morita classified the absence of CT in 1935. Dilli-Babu and Khrab evaluated the CT variations in 16 types, and they aimed to complete the missing aspects of the previous classifications with the addition of CIPA, RIPA, and LIPA variations that were not included in the previous classification. However, the variations like the rare presence of arteries (such as the middle colic artery or suprarenal artery), or variations such as $\mathrm{CHA}$, which do not participate in the pentafurcation in the cadaver instead of the classical trifurcation by Nossol et al., did not find a place in this classification. ${ }^{[12,20-22]}$

While Ferrari et al. reported the rate of normal trifurcation as $56.7 \%$, and normal CHA as $60 \% .{ }^{[23]}$ De Cecco et al. found the variation rate as $34 \%$ in hepatic arteries. ${ }^{[24]}$

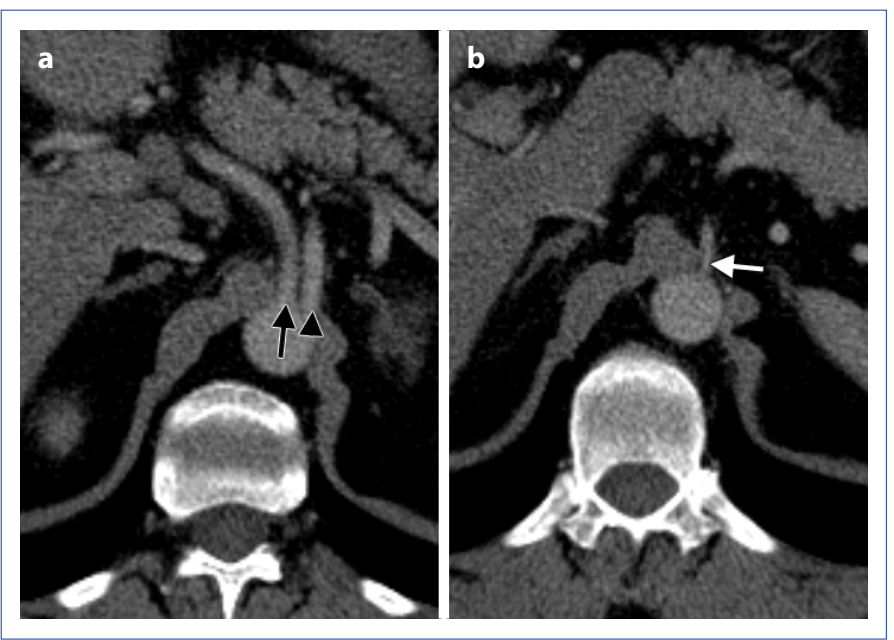

Figure 1. Absence of Celiac Trunk (a) CHA and SA's separation from the aorta (b) LGA's separation from the aorta (the same patient), black arrow: CHA, black arrowhead: SA, white arrow: LGA. CHA: Common hepatic artery, SA: Splenic artery, LGA: Left gastric artery.
The least reported variation among incomplete $\mathrm{CT}$ variations is the gastrosplenomesenteric trunk, which we did not encounter in our cases either.

In the description of Bergman et al., except for variations reported in many other publications, one branch of the CT can pass through the esophageal hiatus to feed the lower middle quadrant of the right lung, or in the absence of one of the $\mathrm{CT}$ branches, it can emerge as a common root with the inferior phrenic artery and can be replaced by the right middle adrenal artery and right gastroepiploic artery or, more rarely, by another branch. ${ }^{[25]}$

Anastomoses are one of the variations that are not emphasized much in MSCT studies. These anastomoses can be parietal or visceral. Parietal collaterals are defined by inferior phrenic arteries, while visceral ones are defined within middle colic, gastroduodenal, and pancreatic arteries. ${ }^{[13,26]}$

There is only one study of anastomoses formed by inferior phrenic arteries. ${ }^{[15]}$ The arc of Buhler (celiacomesenteric anastomosis) has been reported as a remnant of ventral anastomoses and is between SMA and CT or its branches. Dubel et al. determined that the short arc widened by bending in the case of CT stenosis or aneurysmal dilatation. ${ }^{[27,28]}$

In the MSCT angiography study by Ognjanovic et al., the arc of Buhler was imaged in $3 \%$ of cases. ${ }^{[29]}$ In Whitley et al.'s meta-analysis, the presence of this arc with a pooled prevalence of $1.71 \%$; contributes to the continuation of the vitality, especially by ensuring the continuity of liver blood supply. ${ }^{[13]}$ We believe that if the presence of this arch is seen in radiological imaging methods, this should be reported in the reporting.

Other than the arc of Buhler, collaterals can be seen between the superior pancreaticoduodenal artery, which is the GDA branch, and the lower pancreaticoduodenal artery, which is the SMA branch, or between the SMA and the aberrant middle colic artery, if the aberrant middle colic artery is derived from the CT branches. ${ }^{[10,30]}$

In the cadaveric study of Pinal-Garcia et al., normal CT was reported as $43.6 \%$, classical type $7.1 \%$, and non-classical type $36.4 \% \cdot{ }^{[31]}$ Araujo-Neto et al. found normal CT as $90 \%$, Farghadani et al. found $63.9 \%$, and Clement et al. found the normal CT frequency to be $90.5 \%$ in their cadaveric and radiological studies. ${ }^{[32-34]}$

An incomplete trunk can be defined as the absence of one of these three branches or originating from another origin. In this case, it is seen as GST (Fig. 2) HST (Fig. 3), or HGT. In cases, where the $\mathrm{CT}$ is not seen, these three arteries may originate from various structures. The division of the CT with the SMA as a single root from the aorta is also called 


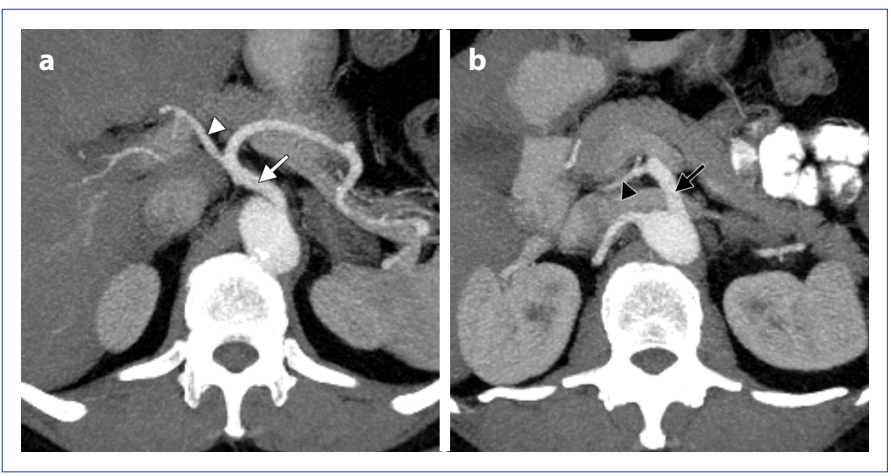

Figure 2. (a) GST originated LHA (b) SMA originated RHA (the same patient), white arrow: GST, white arrow head: LHA, black arrow: SMA, black arrowhead: RHA. GST: Gastrosplenic trunk, LHA: Left hepatic artery, SMA: Superior mesenteric artery, RHA: Right hepatic artery.

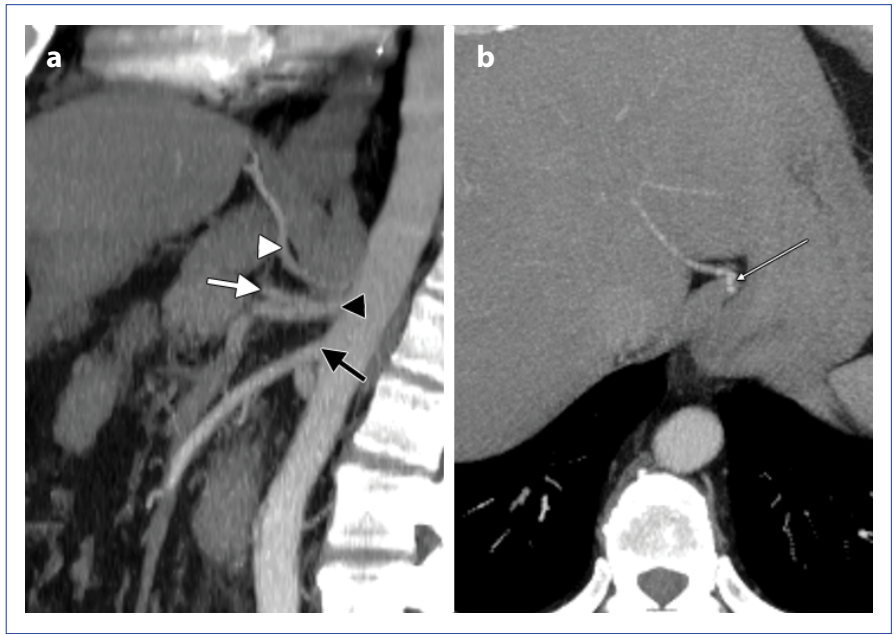

Figure 3. (a) HST (Sagittal MIP image) (b) accessory LHA (the same patient), black arrow: SMA, black arrowhead: HST, white arrow: CHA, white arrowhead: LGA, thin white arrow: Accessory LHA. HST: Hepatosplenic trunk, LHA: Left hepatic artery, SMA: Superior mesenteric artery, LGA: Left gastric artery, CHA: Common hepatic artery.

the CMT (Fig. 4).

In 1994, Hiatt reported that the classification of Michel's could be shortened in the form of five major types and six very rare variants, and called the variation in which $\mathrm{CHA}$, which is not in the Michel's classification, was directly separated from the aorta, as Type VI. ${ }^{[6]}$

Michel's classification does not include only CHA, RHA, and LHA arising from the aorta. Hiatt's classification does not include the variations in which the RHA or LHA arises from the aorta and the variations in which the accessory arteries arise from the aorta (Fig. 5).

Michels determined that the classical trifurcation stated in textbooks is found in only $55 \%$ of the population. Michels opposed the attribution of variational arteries related to hepatic arteries as accessories. Michels stated

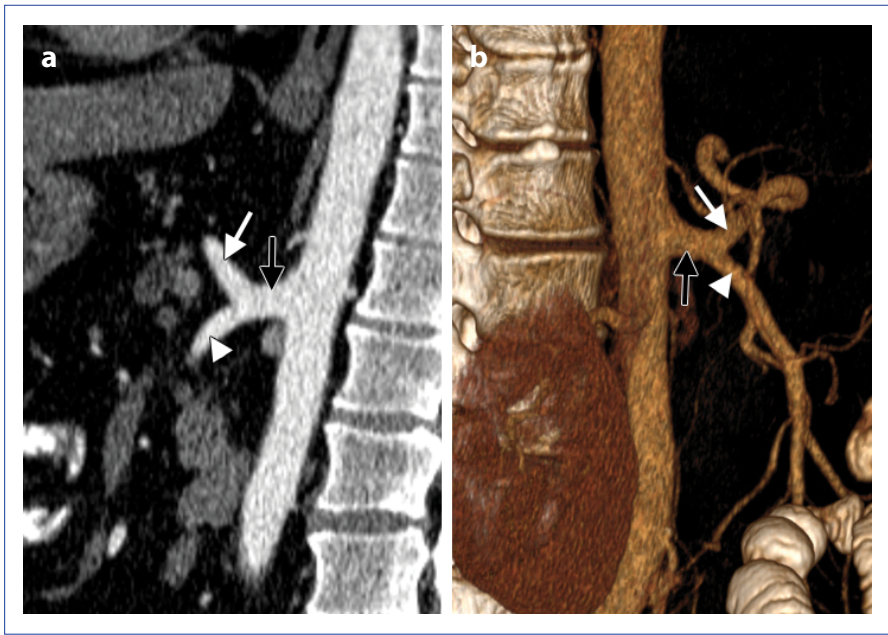

Figure 4. Complete CMT (a) sagittal MIP image (b) 3D image (the same patient) black arrow: CMT, white arrow: $C T$, white arrow head: SMA. CMT: Celiaco-mesenteric trunk, SMA: Superior mesenteric artery, CT: Celiac Trunk.
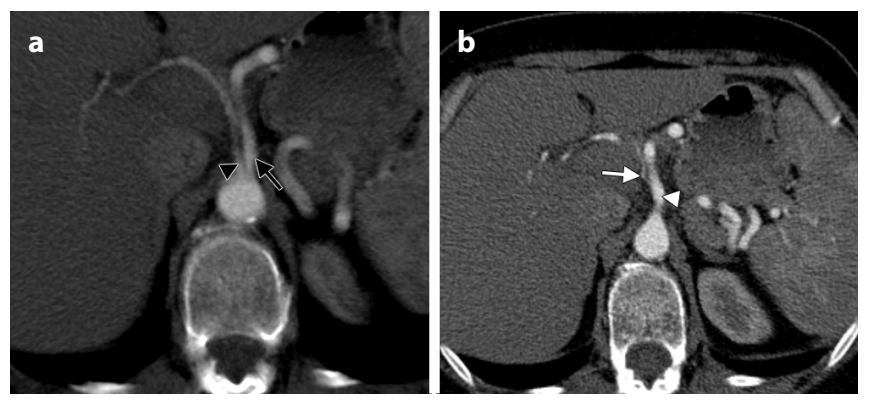

Figure 5. Variation not included in the Michels classification (a) GST and aorta originated CHA (b) LHA's separation from SMA (the same patient), black arrow: GST, black arrowhead: RHA, white arrow: LHA, white arrowhead: SMA. GST: Gastrosplenic trunk, LHA: Left hepatic artery, SMA: Superior mesenteric artery, RHA: Right hepatic artery, CHA: Common hepatic artery.

that these arteries are end-arteries, that if sacrificed, it will cause necrosis, and emphasized the importance of LHA originating from LGA or RHA originating from SMA being the only vessel that feeds this region and used the term replace. Besides hepatic arteries do not form anastomosis in the liver.

Collaterals between CT and SMA in mesenteric vascular structures are reported to be quite incomplete in MSCT studies, and their presence may be overlooked in examination reports. However, its effect on blood supply is certain (Fig. 6). Collateralization with phrenic arteries has been reported most frequently in the literature. Although no correlation was found between $\mathrm{CT}$, hepatic artery variations, and collaterals in our study, it can be said that collaterals between CHA and SMA are seen relatively more common in cases of the single accessory LHA originating 


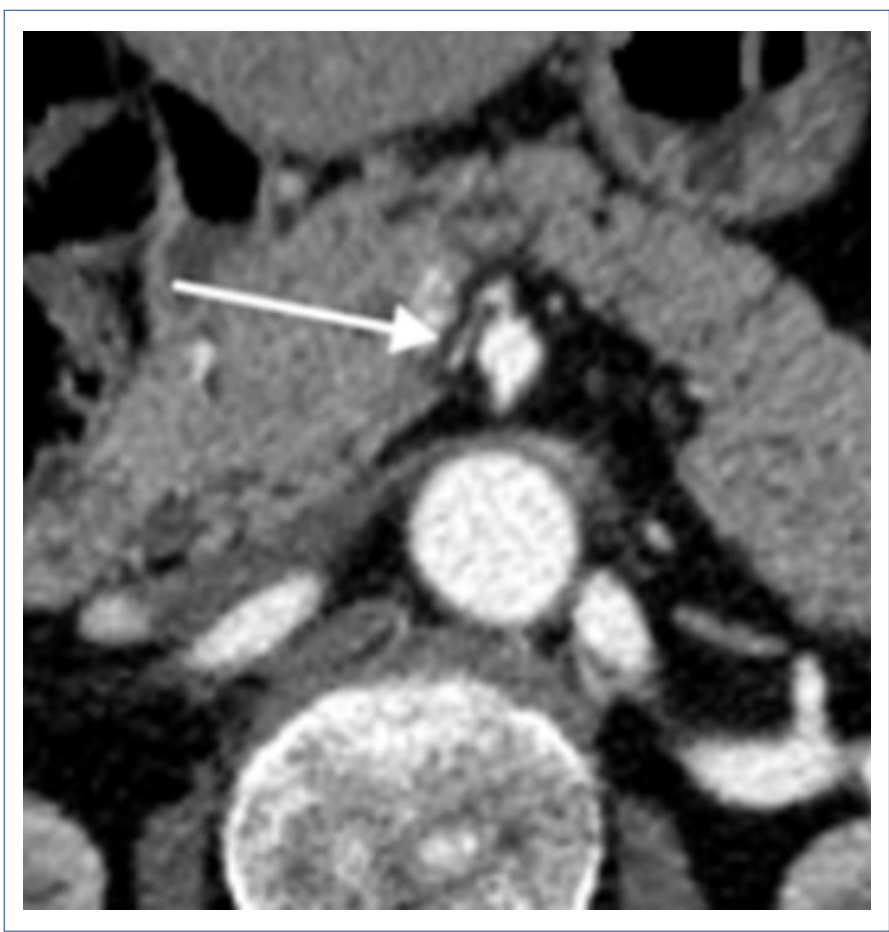

Figure 6. Collateral branch separating from superior mesenteric artery (white arrow).

from the LGA such as Michel Type V and Type VIII.

Vascular anatomy should be known before the operation to use the liver tissue taken from the living donor and to maintain supply of the remaining part in the donor in liver transplantations performed frequently today. ${ }^{[35]}$

Our rates of hepatic artery variation are similar to those of Ugurel et al., who found the most frequency of variations in the literature (48\%) and reported rates in the Turkish population like ours. ${ }^{[36]}$ In the previous studies; however, these rates varied between $16 \%$ and $42 \%$. This situation suggests that there may be more prominent ethnic differences than expected.

CT diameters are measured in fewer papers, and the findings of cadaver and MSCT studies are similar. ${ }^{[32,37,38]}$ Since cadaver studies are a more prominent method in terms of showing the distal continuity of very thin vessels, detailed studies in large series to evaluate collaterals will contribute to the detailed examination of the mesenteric arterial system.

Compared to the previous literature, the relatively high incidence of collateral in our patient group could be secondary to ethnic differences, new collateral growth in colorectal cancer patients, atherosclerosis due to the relatively advanced age in our study group, even dietary habits. Therefore, we think that the assessment of collateral development in various age groups and patient groups would be informative.

\section{Conclusion}

The frequency of the CT and hepatic artery variations we detected in our study is parallel to the data of previous cadaver studies, operation findings, angiography, and MSCT. It has been accepted that the similarity of these rates means that the frequency of variation is not different in colorectal cancer patients. It was aimed to contribute to the literature with diameter and distance measurements that were rarely studied before. In addition, attention was drawn to the presence of collateral arteries in this study. It was thought that the frequency of celiacomesenteric anastomoses should be studied in various age and patient groups and in larger series.

\section{Disclosures}

Ethics Committee Approval: This study was approved by the Local Ethics Committee (Ankara Medipol University, 74791132604.01.01/722).

Peer-review: Externally peer-reviewed.

Conflict of Interest: None declared.

Authorship Contributions: Concept - F.C., M.K., M.A.G.; Design F.C., M.K., M.A.G.; Supervision - F.C., M.K., M.A.G.; Materials - F.C.; Data collection \&/or processing - F.C., M.K.; Analysis and/or interpretation - F.C., M.K., M.A.G.; Literature search - F.C.; Writing - F.C., M.K., M.A.G.; Critical review - F.C., M.K.

\section{References}

1. White RD, Weir-McCall JR, Sullivan CM, Mustafa SA, Yeap PM, Budak MJ, et al. The celiac axis revisited: anatomic variants, pathologic features, and implications for modern endovascular management. Radiographics 2015;35:879-98. [CrossRef]

2. Zhao Y, Fang Z, Luo J, Liu Q, Xu G, Pan H, et al. Evaluation of extrahepatic collateral arteries in hepatocellular carcinoma in three independent groups in a single center. Exp Ther Med 2015;10:2366-74. [CrossRef]

3. Özgür Kuzdan M, Alim A, Alim R, Çelebi S, Özaydın S, Karaaslan B, et al. Giant infantile hepatic hemangioma: case report and surgical technique. Sisli Etfal Hastan Tip Bul 2020;54:108-12. [CrossRef]

4. Nas ÖF, Öngen G, Hacıkurt K, Şanal B, Gökalp G, Durmuş Y, et al. Utilization of different agents in selective embolization of emergency arterial bleeding. Sisli Etfal Hastan Tip Bul 2016;50:280-6.

5. Gore RM, Levine MS. Diseases of the upper GI tract. In: Hodler J, Kubik-Huch RA, von Schulthess GK, editors. Diseases of the abdomen and pelvis. Springer; 2018. p. 91-8. [CrossRef]

6. Uflacker R. Atlas of vascular anatomy: an angiographic approach. 2nd ed. Philadelphia: Lippincott Williams \& Wilkins; 2007.

7. Michels NA. Newer anatomy of the liver and its variant blood supply and collateral circulation. Am J Surg 1966;112:337-47. [CrossRef]

8. Hiatt JR, Gabbay J, Busuttil RW. Surgical anatomy of the hepatic arteries in 1000 cases. Ann Surg 1994;220:50-2. [CrossRef] 
9. Fasel JH, Muster M, Gailloud P, Mentha G, Terrier F. Duplicated hepatic artery: radiologic and surgical implications. Acta Anat (Basel) 1996;157:164-8. [CrossRef]

10. De Martino RR. Normal and variant mesenteric anatomy. In: Mesenteric vascular disease. Oderich GS, editor. Springer; 2015. p. 9-23. [CrossRef]

11. Vesalius A. De humani corporis fabrica libri septem. Basel: Johannes Oporin; 1543.

12. Adachi B, Hasebe K. Das Arteriensystem der Japaner. Kyoto: Kaiserlich-Japanischen Universitaüt; 1928.

13. Whitley A, Oliverius $M$, Kocián $P$, Havlůj L, Gürlich R, Kachlík D. Variations of the celiac trunk investigated by multidetector computed tomography: Systematic review and meta-analysis with clinical correlations. Clin Anat 2020;33:1249-62. [CrossRef]

14. Von Haller A. Icones anatomicae quibus praecipuae aliquae partes corporis humani delineatae proponuntur \& arteriarum potissimum historia. Gottingen: Vandenhoeck; 1756.

15. Aslaner R, Pekcevik Y, Sahin H, Toka O. Variations in the origin of inferior phrenic arteries and their relationship to celiac axis variations on CT angiography. Korean J Radiol 2017;18:336-44. [CrossRef]

16. Poynter CWM. Congenital anomalies of the arteries and veins of the human body with bibliography. Lincoln: University of Nebraska; 1922.

17. Matusz P, Miclaus GD, Ples $H$, Tubbs RS, Loukas M. Absence of the celiac trunk: case report using MDCT angiography. Surg Radiol Anat 2012;34:959-63. [CrossRef]

18. Yalçin B, Kocabiyik N, Yazar F, Ozan H, Ozdogmus O. Variations of the branches of the celiac trunk. Gülhane Med J 2004;46:163-5.

19. Erkoc MF, Kantarci M, Okur A, Kizrak Y, Sipahi M. Multislice computed tomography angiography of an extremely uncommon variation of hepatic arteries: Michel's Type XI. Ann Vasc Surg 2015;29:842.e1-3. [CrossRef]

20. Morita M. Reports and conception of three anomalous cases in the area of the celiac and superior mesenteric arteries. Igaku Kenkyu (Acta Medica) 1935;9:159-72.

21. Dilli-Babu E, Khrab P. Coeliac trunk variations: review with proposed new classification. Int J Anat Res 2013;1:165-70.

22. Nossol C, Henel S, Brosch J, Junghans CM, Laddey O, Bartel S et al. A rare variation of the celiac trunk: a case report. Eur J Anat 2016;20:361-3.

23. Ferrari $R$, De Cecco CN, lafrate F, Paolantonio $P$, Rengo M, Laghi A. Anatomical variations of the coeliac trunk and the mesenteric arteries evaluated with 64-row CT angiography. Radiol Med 2007;112:988-98. [CrossRef]

24. De Cecco CN, Ferrari R, Rengo M, Paolantonio P, Vecchietti F, Laghi A. Anatomic variations of the hepatic arteries in 250 patients stud- ied with 64-row CT angiography. Eur Radiol 2009;19:2765-70.

25. Bergman RA, Afifi AK, Jew JY, Reimann PC. Atlas of human anatomy in cross section. Baltimore: Urban and Schwarzenberg; 1991.

26. Gwon DI, Ko GY, Yoon HK, Sung KB, Lee JM, Ryu SJ, et al. Inferior phrenic artery: anatomy, variations, pathologic conditions, and interventional management. Radiographics 2007;27:687-705.

27. Dubel GJ, Ahn SH, Saeed MA. Interventional management of arc of buhler aneurysm. Semin Intervent Radiol 2007;24:76-81.

28. Bühler A. Über eine anastomose zwischen den stammen der art. celiaca und art. mesenterica superior. Morphologisches Jahrbuch 1904;32:185-8.

29. Ognjanovic N, Jeremic D, Zivanovic-Macuzic I, Sazdanovic M, Sazdanovic P, Tanaskovic I, et al. MDCT angiography of anatomical variations of the celiac trunk and superior mesenteric artery. Arch Biol Sci 2014;66:233-40. [CrossRef]

30. Kwong MLM, Pelton J. Middle colic artery originating from the gastroduodenal artery discovered during a whipple. Case Rep Surg 2019;2019:1986084. [CrossRef]

31. Pinal-Garcia DF, Nuno-Guzman CM, Gonzalez-Gonzalez ME, Ibarra-Hurtado TR. The celiac trunk and its anatomical variations: a cadaveric study. J Clin Med Res 2018;10:321-9. [CrossRef]

32. Araujo Neto SA, de Mello Júnior CF, Franca HA, Duarte CM, Borges RF, de Magalhães AG. Multidetector computed tomography angiography of the celiac trunk and hepatic arterial system: normal anatomy and main variants. Radiol Bras 2016;49:49-52. [CrossRef]

33. Farghadani M, Momeni M, Hekmatnia A, Momeni F, Baradaran Mahdavi MM. Anatomical variation of celiac axis, superior mesenteric artery, and hepatic artery: Evaluation with multidetector computed tomography angiography. J Res Med Sci 2016;21:129.

34. Marco-Clement I, Martinez-Barco A, Ahumada N, Simon C, Valderrama JM, Sanudo J, et al. Anatomical variations of the celiac trunk: cadaveric and radiological study. Surg Radiol Anat 2016;38:50110. [CrossRef]

35. Broelsch CE, Malagó M, Testa G, Valentin Gamazo C. Living donor liver transplantation in adults: outcome in Europe. Liver Transpl 2000;6:S64-5. [CrossRef]

36. Ugurel MS, Battal B, Bozlar U, Nural MS, Tasar M, Ors F, et al. Anatomical variations of hepatic arterial system, coeliac trunk and renal arteries: an analysis with multidetector $\mathrm{CT}$ angiography. $\mathrm{Br} \mathrm{J}$ Radiol 2010;83:661-7. [CrossRef]

37. Panagouli E, Venieratos D, Lolis E, Skandalakis P. Variations in the anatomy of the celiac trunk: A systematic review and clinical implications. Ann Anat 2013;195:501-11. [CrossRef]

38. Silveira LA, Silveira FB, Fazan VP. Arterial diameter of the celiac trunk and its branches. Anatomical study. Acta Cir Bras 2009;24:43-7. [CrossRef] 